\title{
FMEA como subsídio para a implementação do sistema de gestão ambiental em laboratório da UFRA
}

O Sistema de Gestão Ambiental (SGA), cada vez mais aplicado pelas instituições, tem por finalidade proporcionar qualidade ambiental ao processo produtivo. Nesse contexto, a metodologia FMEA (Failure Mode and Effects Analysis - Análise dos Modos de Falha e seus Efeitos) é uma importante ferramenta para subsidiar a implementação do SGA nas instituições de pesquisa, como os dos laboratórios de análises químicas, que são potenciais para a instalação de impactos ambientais. O objetivo deste estudo foi analisar a aplicação de FMEA no Laboratório de Química do Solo da Universidade Federal Rural da Amazônia (UFRA), em Belém-PA. Os resultados demonstraram a existência de oito problemas, sendo que os principais são: o despejo inadequado de efluentes, a má gestão de água e o descarte inadequado de resíduos, que devem ter ações corretivas prioritárias; assim como, de imediato, mudanças na postura dos profissionais quanto ao uso e gestão dos recursos laboratoriais, a fim de melhorar o processo de análises químicas. Os demais resultados também devem ser corrigidos, porém não de imediato, e sim, a médio e/ou a longo prazo. O método FMEA demostrou ser eficiente na identificação e avaliação dos riscos ambientais, nas causas e nos efeitos in loco, propondose ações preventivas e/ou corretivas e gerando subsídios para a implementação do SGA.

Palavras-chave: Atividades Laboratoriais; Gestão Ambiental; Impacto Ambiental; Risco Ambiental.

\section{FMEA as a subsidy for the implementation of the UFRA laboratory environmental management system}

The Environmental Management System (EMS), increasingly applied by the institutions, aims to provide environmental quality to the production process. In this context, the FMEA (Failure Mode and Effects Analysis) methodology is an important tool to subsidize the implementation of EMS in research institutions, such as chemical analysis laboratories, which are potential for installation of environmental impacts. The objective of this study was to analyze the application of FMEA in the Soil Chemistry Laboratory of the Federal Rural University of Amazonia (UFRA), in Belém-PA. The results showed the existence of eight problems, the main ones being: inadequate effluent disposal, poor water management and inadequate waste disposal, which should have priority corrective actions; as well as, immediately, changes in the professionals' posture regarding the use and management of laboratorial resources, in order to improve the chemical analysis process. The other results should also be corrected, but not immediately, but in the medium and/or long term. The FMEA method has proved to be efficient in identifying and evaluating environmental risks, causes and effects in loco, proposing preventive and/or corrective actions and generating subsidies for the implementation of the EMS.

Keywords: Laboratory Activities; Environmental Management; Environmental Impact; Environmental Risk.

Topic: Engenharia Ambiental

Reviewed anonymously in the process of blind peer.
Received: $10 / 08 / 2018$

Approved: 24/09/2018
Kelly Christina Alves Bezerra

Universidade do Estado do Pará, Brasil

http://lattes.cnpq.br/4256212364273456

engambkelly@gmail.com

Yan Nunes Dias (DD

Universidade Federal Rural da Amazônia http://lattes.cnpq.br/0385219731300329 http://orcid.org/0000-0002-4058-9433 yanynd1@gmail.com

Raynon Joel Monteiro Alves (it)

Universidade do Estado do Pará, Brasil

http://lattes.cnpq.br/8830660963340545

http://orcid.org/0000-0002-8091-4464

raynon alves@yahoo.com.br

\author{
Hélio Raymundo Ferreira Filho (id \\ Universidade do Estado do Pará, Brasil \\ http://lattes.cnpq.br/2760498204696515 \\ http://orcid.org/0000-0002-4802-9166 \\ helio.ferreira@uepa.br \\ Altem Nascimento Pontes (iD \\ Universidade do Estado do Pará, Brasil \\ http://lattes.cnpq.br/5993352890364998 \\ http://orcid.org/0000-0002-9001-4603 \\ altempontes@hotmail.com
}

Referencing this:

BEZERRA, K. C. A.; DIAS, Y. N.; ALVES, R. J. M.; FERREIRA FILHO, H. R.; PONTES, A. N.. FMEA como subsídio para a implementação do sistema de gestão ambiental em laboratório da UFRA. Revista Ibero Americana de Ciências Ambientais, v.9, n.7, p.149-157, 2018. DOI: http://doi.org/10.6008/CBPC2179-6858.2018.007.0014 


\section{INTRODUÇÃO}

O Sistema de Gestão Ambiental (SGA) tem se destacado devido ao interesse de eliminar os impactos negativos e preservar a imagem de uma instituição (OLIVEIRA et al., 2010; LIMA et al., 2012). O SGA desenvolve e implementa a política ambiental, além de gerenciar os aspectos ambientais (ABNT, 2004b), a fim de prevenir o impacto ao invés de remediá-lo. Tal sistema se trata de uma relevante ferramenta para a disseminação da cultura da preservação ambiental (OLIVEIRA et al., 2010; BRENDLER et al., 2011) em locais de trabalho.

A implementação do SGA pode ser auxiliada pelo uso da metodologia de Análise dos Modos de Falhas e seus Efeitos - FMEA (Failure Mode and Effects Analysis), que é um instrumento para fazer a avaliação da qualidade ambiental. De acordo com Grael et al. (2010), neste sentido, há condições de ampliar o desempenho ambiental, que é um dos principais objetivos das instituições.

O método FMEA identifica as falhas reais ou potenciais em cada fase do processo produtivo, estabelecendo erros prioritários para eliminação ou minimização de seus impactos ambientais, além de planejar melhorias no processo ou produto e reduzir os custos por meio de ações preventivas de falhas (LAURENTI et al., 2012; FRANK et al., 2014). Dessa forma, a aplicação da FMEA pode subsidiar o melhoramento significativo do perfil de trabalho e de produção das instituições, em geral, de forma sustentável.

A metodologia FMEA, para tanto, colabora na tomada de decisão, envolvendo riscos, no cumprimento da legislação e na obtenção da certificação ambiental (GARCIA, 2013). Essa metodologia também está relacionada com os requisitos da norma ISO 14000, visando ampliar a visão das causas e dos efeitos das falhas, que são inconformidades na produção e, desta forma, facilitar a implementação do SGA por meio do mapeamento das questões ambientais da área avaliada (OLIVEIRA et al., 2010).

Neste sentido, a FMEA pode ser aplicada em laboratórios de análises clínicas das Instituições de Ensino Superior (IES), como no caso dos Laboratórios de Análise de Solos da Universidade Federal Rural da Amazônia (UFRA), visto que as atividades desenvolvidas nesse laboratório podem acarretar danos à saúde humana e ambiental, como por exemplo, a poluição e/ou contaminação dos corpos hídricos e do solo (PENATTI et al., 2011). Desse modo, a FMEA pode contribuir na minimização ou eliminação dos possíveis impactos negativos que tais atividades podem ocasionar na natureza e na sociedade.

Diante do exposto, este estudo objetivou analisar a aplicação do método FMEA para avaliação dos riscos ambientais no Laboratório de Química do Solo da Universidade Federal Rural da Amazônia, em BelémPA, a fim de gerar subsídios importantes para a implementação do Sistema de Gestão Ambiental (SGA) da instituição.

\section{METODOLOGIA}

O método de pesquisa adotado foi o de estudo de caso no Laboratório de Química do Solo, localizado no Prédio de Solos da Universidade Federal Rural da Amazônia (UFRA), Campus Belém/PA. Nesse laboratório 
são realizadas análises de cálcio $(\mathrm{Ca})$, magnésio $(\mathrm{Mg})$, potássio $(\mathrm{K})$, fósforo $(\mathrm{P})$, alumínio $(\mathrm{Al})$ e $\mathrm{pH}$ em $\mathrm{H}_{2} \mathrm{O}$, de forma isolada; e depois, somadas ao carbono orgânico $\left(\mathrm{C}_{\text {org }}\right)$, sódio $(\mathrm{Na})$ e hidrogênio mais alumínio $(\mathrm{H}+\mathrm{Al})$, além do nitrogênio (N), visando avaliar a fertilidade do solo, utilizando a metodologia da Embrapa (2011).

O referido estudo foi realizado em abril de 2017, a partir do preenchimento do formulário FMEA, de forma conjunta, pelos autores do presente estudo, com base em pesquisas já desenvolvidas por Zambrano et al. (2007) e Nogueira et al. (2011). Os aspectos considerados na avaliação desse formulário foram: a descrição das saídas (função, tipo, efeitos do impacto ambiental, causa do impacto ambiental e controles atuais) e as ações recomendadas (controles ambientais).

O item função corresponde à descrição das saídas das atividades laboratoriais desenvolvidas e à função exercida durante o processo de análise química. 0 tipo está relacionado à classificação do impacto ambiental em real (R), caso já ocorra no laboratório, ou potencial $(\mathrm{P})$, se houver a possibilidade de ocorrência. Os efeitos do impacto ambiental descrevem os meios envolvidos com o impacto ambiental, podendo ser a água, o solo e/ou o ar. A causa do impacto ambiental é o motivo que provoca o impacto ambiental durante as análises laboratoriais desenvolvidas. Os controles atuais envolvem as atitudes adotadas pela instituição para impedir a ocorrência do impacto ambiental. Os controles ambientais - do item ações recomendadas descrevem as ações que a instituição deve adotar, a fim de eliminar ou mitigar os impactos ambientais.

As colunas representadas por ' $S$ ', ' $O$ ', ' $D$ ', ' $A$ ' e ' $R$ ' estão relacionadas, respectivamente, às características do impacto ambiental - severidade, ocorrência, detecção e abrangência - e ao risco ambiental. Os valores de 'S', 'O', ' $D$ ' e 'A' são classificados de acordo com sua gravidade em um, dois ou três pontos (Quadro 1). Já o fator $R$ se trata do resultado da multiplicação das pontuações dos quatro índices. Em ambos os casos, quanto maior for a pontuação, maior será a gravidade do impacto ambiental.

Quadro 1: Classificação da severidade, ocorrência, detecção e abrangência do impacto ambiental.

\begin{tabular}{|c|c|c|c|}
\hline Índice & Classificação & Descrição & Valor \\
\hline \multirow{3}{*}{ Severidade } & Baixa & $\begin{array}{l}\text { Produtos pouco danosos ao meio ambiente, que possuem curto tempo de decomposição, } \\
\text { como: papelão e tecidos. }\end{array}$ & 1 \\
\hline & Moderada & $\begin{array}{l}\text { Produtos danosos ao meio ambiente, que possuem longo tempo de decomposição, como: } \\
\text { metais, vidros e plásticos. }\end{array}$ & 2 \\
\hline & Alta & $\begin{array}{l}\text { Produtos muito danosos ao meio ambiente, que possuem características, como: } \\
\text { corrosividade, reatividade, explosividade, toxicidade, inflamabilidade e patogenicidade. }\end{array}$ & 3 \\
\hline \multirow{3}{*}{ Ocorrência } & Baixa & O impacto ambiental ocorre semestral ou anualmente. & 1 \\
\hline & Moderada & O impacto ambiental ocorre mensalmente. & 2 \\
\hline & Alta & O impacto ambiental ocorre diariamente. & 3 \\
\hline \multirow{3}{*}{ Detecção } & Baixa & O impacto ambiental é detectado utilizando tecnologias sofisticadas. & 3 \\
\hline & Moderada & $\begin{array}{l}\text { O impacto ambiental é detectado utilizando medidores simples como: hidrômetro e medidor } \\
\text { de energia elétrica. }\end{array}$ & 2 \\
\hline & Alta & O impacto ambiental é detectado visualmente. & 1 \\
\hline \multirow{3}{*}{ Abrangência } & Pequena & O impacto ambiental ocorre no local onde está sendo realizada a operação. & 1 \\
\hline & Moderada & O impacto ambiental ocorre dentro dos limites da organização. & 2 \\
\hline & Grande & O impacto ambiental ocorre fora dos limites da organização. & 3 \\
\hline
\end{tabular}

Fonte: Adaptado de Nogueira et al. (2011).

\section{RESULTADOS}

Os resultados da aplicação do método FMEA no Laboratório de Química do Solo da UFRA, Campus Belém/PA, estão expostos abaixo (Quadro 2). 
Quadro 2: Análise do formulário da FMEA aplicado ao Laboratório de Química do Solo (UFRA).

\begin{tabular}{|c|c|c|c|c|c|c|c|c|c|c|}
\hline Descrição & Índices & Controles ambientais & & & & & & & & \\
\hline Função & Tipo & $\begin{array}{l}\text { Efeito do impacto } \\
\text { ambiental }\end{array}$ & $\begin{array}{l}\text { Causa do impacto } \\
\text { ambiental }\end{array}$ & $\begin{array}{l}\text { Controles } \\
\text { atuais }\end{array}$ & $\mathbf{S}$ & 0 & D & A & $\mathbf{R}$ & Ações recomendadas \\
\hline $\begin{array}{l}\text { Despejo } \\
\text { inadequado } \\
\text { de efluentes. }\end{array}$ & $\mathrm{R}$ & $\begin{array}{l}\text { Poluição/contaminação } \\
\text { do meio ambiente. }\end{array}$ & $\begin{array}{l}\text { Descarte dos } \\
\text { efluentes } \\
\text { diretamente no } \\
\text { solo ou pela pia. }\end{array}$ & $\begin{array}{l}\text { Não } \\
\text { existe. }\end{array}$ & 3 & 3 & 1 & 3 & 27 & $\begin{array}{lr}\text { Implementação } & \text { de } \\
\text { uma Estação de } & \text { dratamento } \\
\text { Efluentes e de um } \\
\text { Programa } \\
\text { Gerenciamento de } \\
\text { Resíduos Químicos. }\end{array}$ \\
\hline $\begin{array}{l}\text { Má gestão do uso } \\
\text { da água. }\end{array}$ & $\mathrm{R}$ & $\begin{array}{l}\text { Diminuição de recursos } \\
\text { hídricos propícios para a } \\
\text { atividade e contaminação } \\
\text { da água servida. }\end{array}$ & $\begin{array}{l}\text { Uso exagerado de } \\
\text { água para lavagem } \\
\text { de aparatos } \\
\text { laboratoriais e } \\
\text { falta de } \\
\text { tratamento desta } \\
\text { água. }\end{array}$ & $\begin{array}{l}\text { Não } \\
\text { existe. }\end{array}$ & 2 & 3 & 1 & 3 & 18 & $\begin{array}{l}\text { Incentivo ao uso } \\
\text { racional da água e o } \\
\text { reaproveitamento da } \\
\text { água servida, após } \\
\text { tratamento pela ETE. }\end{array}$ \\
\hline $\begin{array}{l}\text { Destinação } \\
\text { inadequada } \\
\text { de resíduos. }\end{array}$ & $\mathrm{R}$ & $\begin{array}{l}\text { Poluição/contaminação } \\
\text { do meio ambiente. }\end{array}$ & $\begin{array}{l}\text { Solo com resíduo } \\
\text { de solução. }\end{array}$ & $\begin{array}{l}\text { Não } \\
\text { existe. }\end{array}$ & 3 & 3 & 1 & 2 & 18 & $\begin{array}{l}\text { Implementação de um } \\
\text { Plano de } \\
\text { Gerenciamento de } \\
\text { Resíduos Sólidos. }\end{array}$ \\
\hline $\begin{array}{l}\text { Armazenamento } \\
\text { de amostras } \\
\text { inutilizadas. }\end{array}$ & $\mathrm{R}$ & $\begin{array}{l}\text { Ocupação indevida do } \\
\text { espaço físico. }\end{array}$ & $\begin{array}{l}\text { Má gestão do } \\
\text { espaço, devido ao } \\
\text { arranjo físico } \\
\text { inadequado. }\end{array}$ & $\begin{array}{l}\text { Não } \\
\text { existe. }\end{array}$ & 2 & 3 & 1 & 2 & 12 & $\begin{array}{l}\text { Implementação de um } \\
\text { Plano de } \\
\text { Gerenciamento de } \\
\text { Resíduos Sólidos e de } \\
\text { um Plano de } \\
\text { Gerenciamento de } \\
\text { Resíduos Químicos. }\end{array}$ \\
\hline $\begin{array}{l}\text { Utilização de } \\
\text { equipamentos, } \\
\text { vidrarias e } \\
\text { descartáveis. }\end{array}$ & $\mathrm{R}$ & $\begin{array}{l}\text { Maior quantidade de } \\
\text { resíduos gerados pós- } \\
\text { consumo. }\end{array}$ & $\begin{array}{l}\text { Uso de copos } \\
\text { descartáveis para } \\
\text { análise de } \mathrm{pH} \text {. }\end{array}$ & $\begin{array}{l}\text { Não } \\
\text { existe. }\end{array}$ & 2 & 3 & 1 & 2 & 12 & $\begin{array}{l}\text { Redução da utilização } \\
\text { de descartáveis e a } \\
\text { implementação de um } \\
\text { Programa de Controle } \\
\text { de Qualidade. }\end{array}$ \\
\hline $\begin{array}{l}\text { Acúmulo de } \\
\text { aparatos } \\
\text { laboratoriais } \\
\text { inutilizados. }\end{array}$ & $R$ & $\begin{array}{l}\text { Acúmulo de poeira e } \\
\text { agentes que podem } \\
\text { comprometer a saúde e } \\
\text { alterar as análises. }\end{array}$ & \begin{tabular}{l}
\multicolumn{2}{l}{ Equipamentos, } \\
caixas, sacos e \\
vidraria $\quad$ em \\
desuso.
\end{tabular} & $\begin{array}{l}\text { Não } \\
\text { existe. }\end{array}$ & 2 & 3 & 1 & 1 & 6 & $\begin{array}{lr}\text { Implementação de um } \\
\text { Plano } & \text { de } \\
\text { Gerenciamento } & \text { de } \\
\text { Resíduos Sólidos. } & \end{array}$ \\
\hline $\begin{array}{l}\text { Desperdício de } \\
\text { energia elétrica. }\end{array}$ & $\mathrm{R}$ & $\begin{array}{l}\text { Maior exploração de } \\
\text { recursos naturais por } \\
\text { causa do desperdício de } \\
\text { energia elétrica. }\end{array}$ & $\begin{array}{l}\text { Luzes acessas em } \\
\text { situações } \\
\text { desnecessárias. }\end{array}$ & $\begin{array}{l}\text { Não } \\
\text { existe. }\end{array}$ & 1 & 3 & 1 & 2 & 6 & $\begin{array}{l}\text { Incentivo ao consumo } \\
\text { racional e eficiente de } \\
\text { energia. }\end{array}$ \\
\hline $\begin{array}{l}\text { Armazenamento } \\
\text { de reagentes } \\
\text { vencidos. }\end{array}$ & $\mathrm{R}$ & $\begin{array}{l}\text { Possibilidade de acidentes } \\
\text { com vapores e substâncias } \\
\text { químicas. }\end{array}$ & $\begin{array}{l}\text { Reagentes } \\
\text { vencidos } \\
\text { armazenados } \\
\text { junto com os que } \\
\text { ainda estão na } \\
\text { validade. }\end{array}$ & $\begin{array}{l}\text { Não } \\
\text { existe. }\end{array}$ & 1 & 1 & 1 & 2 & 2 & $\begin{array}{l}\text { Implementação de um } \\
\text { Programa de Controle } \\
\text { de Qualidade. }\end{array}$ \\
\hline
\end{tabular}

\section{DISCUSSÃO}

Com base nas informações da FMEA, obtiveram-se oito funções do Laboratório de Química do Solo, cujos riscos ambientais resultaram de aspectos (causas), principalmente relacionados ao indevido uso e/ou gestão de recursos e dos resíduos destes provenientes (Quadro 2). Neste sentido, considera-se o risco ambiental como a probabilidade de o impacto ambiental vir a ocorrer (ZAMBRANO et al., 2007), sobretudo, quando se trata de um laboratório de pesquisas químicas com ausentes ou insuficientes medidas de prevenção de impactos.

Estes riscos presentes no cotidiano de trabalho (classificados como reais - R), os quais, predominantemente, obtiveram o valor máximo no índice Ocorrência - O (3), evidenciam a suscetibilidade de ocorrência de impactos negativos, como: poluição e/ou contaminação do meio ambiente, comprometimento da saúde humana e superexploração de recursos utilizados nos processos laboratoriais (Quadro 2). Tais riscos ganham maior seriedade quando verificado que não há ações de controles atuais 
desenvolvidas pelos gestores e trabalhadores do Laboratório, apesar de que todos os problemas contidos no FMEA sejam diariamente visíveis a olho nu.

Entre os riscos avaliados o despejo inadequado de efluentes e o de resíduos obtiveram o valor máximo (3) nos índices Severidade (S) e Ocorrência (O), pois se trata do contato direto de substâncias perigosas à saúde ambiental (água, solo, ar, fauna e flora) e humana, visto que o descarte residual ocorre externamente às dependências do laboratório, geralmente sendo destinados às valas - de escoamento das águas das pias -, depósito comum de resíduos ou diretamente no solo, sendo que em todos os casos não há um tratamento antes do descarte. Os riscos ambientais (R) verificados pela FMEA estão abaixo descritos e com suas respectivas ações sugeridas - controles ambientais - para minimizá-los.

\section{O despejo inadequado de efluentes}

Este processo pode acontecer cotidianamente quando os rejeitos são descartados diretamente no terreno do laboratório ou pela pia, em ambos os casos sem nenhum tratamento $(R=27)$ (Quadro 2). Neste caso, deve-se considerar que a água é um importante agente veiculador de substâncias nocivas à saúde humana e ambiental, visto que os efluentes escoam por tubulações em direção ao solo, onde são retidos, podendo provocar, por exemplo, a contaminação edáfica e hídrica.

Diante disso, recomenda-se a instalação de uma Estação de Tratamento de Efluente (ETE), a qual quando se trata de análises químicas - é considerada como uma alternativa ambientalmente correta. É necessário também atender às condições básicas para as atividades laboratoriais: escolher um agente adequado para isolar os elementos presentes nos resíduos; ajustar o pH à faixa ideal; fazer a filtração em meio adequado e eliminar corretamente os redutores ou os oxidantes do efluente (MARINHO et al., 2011).

Propõe-se ainda implementar no referido laboratório um Programa de Gerenciamento de Resíduos Químicos (PGRQ) para subsidiar mudanças quanto ao descarte inadequado de efluentes. Apesar do pequeno volume de efluentes produzidos pelas análises, há uma grande diversidade de compostos químicos, dessa forma exigindo um tratamento específico, dependendo de sua composição. A gestão desses resíduos minimiza os impactos ambientais causados pelas análises laboratoriais, difundindo o hábito da preservação do meio ambiente (BRENDLER et al., 2011).

\section{Má gestão do uso da água e da energia elétrica}

A má gestão do uso da água acontece diariamente durante a lavagem de vidrarias, utensílios e equipamentos usados nas análises químicas $(R=18)$ (Quadro 2). Além de contaminar com substâncias perigosas a água servida, não se tem o devido cuidado com este recurso natural, desperdiçando-o. Geralmente, diversas atividades, utilizam uma quantidade de água superior ao que é necessário, e muitas vezes, não submetem o efluente a um tratamento adequado, consequentemente causando a poluição e/ou contaminação dos recursos hídricos.

Neste sentido, sugere-se um melhor gerenciamento da água para evitar o desperdício como por meio do incentivo ao uso racional deste recurso. Dentre as possíveis medidas para diminuir o desperdício de água 
e preservar sua qualidade estão: a promoção de campanhas de educação ambiental aos funcionários e alunos de determinada instituição; a recomendação para que as IES desenvolvam pesquisas e empreguem técnicas para a conservação desse recurso, além de ações que incentivem o controle de consumo, a redução de desperdício e o reuso de água (CARLI et al., 2013).

Recomenda-se também o tratamento da água pós-consumo pela ETE, podendo ser este recurso reaproveitado, como por exemplo, por meio do reuso de efluentes nas hortas da universidade ou da instalação de um reservatório de água sob a bancada, visando reaproveitá-la para a lavagem dos aparatos laboratoriais (Ibidem). Dependendo de qual seja a aplicação de interesse, a água de reuso pode ser reutilizada nas atividades do laboratório, contanto que o efluente - tratado ou não - atenda aos parâmetros qualitativos e quantitativos requeridos para seu referido uso. Estas são algumas ações que contribuem, inclusive, para a manutenção dos processos produtivos e laboratoriais.

O desperdício de energia elétrica ocorre cotidianamente quando as luzes permanecem acessas no laboratório, sem que haja necessidade $(R=6)$ (Quadro 2). Nestas condições, pode-se afirmar que não se tem o cuidado necessário com este recurso, pois, além do desperdício, tem-se maior exploração das fontes geradoras de energia elétrica. $\mathrm{O}$ uso racional de energia elétrica é o alicerce para se obter uma gestão eficiente desse insumo, que é alicerce para qualquer empreendimento. A UFRA deve desempenhar seu papel como agente educador, praticando o que é ensinado nos cursos graduação e pós-graduação da instituição.

Dessa forma, é fundamental que as universidades exerçam sua função de disseminar conhecimento, assim contribuindo para o combate ao desperdício e o uso eficiente dos recursos naturais. Diante disso, recomenda-se a realização de campanhas que visem capacitar os usuários do laboratório a praticarem técnicas de combate ao desperdício e disseminar o uso racional de energia; além da utilização de sensores de presença, e da substituição, quando viável, da energia elétrica convencional por fontes alternativas e de equipamentos obsoletos por modernos que possuam eficiência energética.

\section{Destinação inadequada de resíduos}

Este é um agravo que ocorre constantemente no laboratório no que diz respeito ao despejo indevido de resíduos (solos analisados) com soluções, sem nenhum tratamento e em locais inapropriados, o que consiste em risco de poluição e contaminação do meio ambiente, conforme anteriormente mencionado $(R=$ 18) (Quadro 2). Em função da diversidade de serviços laboratoriais executados, deve-se considerar que os resíduos das análises químicas apresentam uma complexidade de substâncias. Portanto, cada resíduo deve ser submetido a um tratamento específico e apropriado - de acordo com suas características - a fim de evitar o registro de impactos ambientais negativos.

Recomenda-se a elaboração e implementação de um Plano de Gerenciamento de Resíduos Sólidos (PGRS), que deve estar em conformidade com as legislações ambientais, além de estabelecer as normas norteadoras do manejo de cada tipo de resíduo produzido durante as análises químicas, desde a origem até a destinação final. Todos os resíduos gerados pelas análises realizadas no Laboratório de Química do Solo devem ser classificados em: Resíduos Classe I (perigosos) ou Classe II (Não Perigosos); e submetidos ao 
tratamento adequado (ABNT, 2004a).

\section{Outros}

Neste caso, optou-se em classificar as demais saídas do FMEA pelo critério de uso indevido do espaço e dos aparatos laboratoriais que, neste estudo, estiveram relacionados ao armazenamento de amostras inutilizadas $(R=12)$; a utilização de equipamentos, vidrarias e descartáveis $(R=12)$; o acúmulo de aparatos inutilizados $(R=6)$; e o armazenamento de reagentes vencidos $(R=2)$ (Quadro 2). Essas ações podem ser prejudiciais às análises químicas de materiais biológicos e geológicos, podendo mascarar, comprometer ou inviabilizar os resultados, além de gerar danos e prejuízos ao laboratório.

É sugerível que o PGRS contemple o devido descarte das amostras inutilizadas e de equipamentos em desuso, cujos materiais pós-consumo podem retornar à cadeia produtiva por meio da Logística Reversa, sendo que, na primeira situação, também o PGRQ deve se encarregar dos rejeitos de análises químicas. Já o armazenamento de reagentes vencidos e do constante uso de equipamentos, vidrarias e descartáveis requerem uma gestão de materiais e do processo como um todo, como por meio de um Programa de Controle de Qualidade (PCQ).

O PCQ consiste de um conjunto de ações preventivas, que fornecem informações sobre o desempenho avaliado por meio do monitoramento dos procedimentos. A prestação de um serviço eficiente é assegurada por um controle de qualidade, caracterizado como uma ferramenta essencial para estabelecer ações de caráter corretivo. Dessa forma, aumentar a qualidade é fundamental para otimizar os processos, uma vez que possibilita a diminuição de desperdícios e custos, além da elevação da produtividade. As causas dos impactos ambientais são muito semelhantes: ausência de um planejamento e uma organização, que definam uma avaliação periódica das condições do laboratório e contribuam em sua gestão ambiental.

\section{CONCLUSÕES}

O método FMEA aplicado no laboratório - alvo da pesquisa - evidenciou a existência de oito problemas. Dentre eles, constatou-se que as principais atividades reais para a instalação de impactos ambientais, são o despejo inadequado de efluentes, a má gestão do uso da água e a destinação indevida de resíduos, o que requerem ações corretivas prioritárias. Essas funções apresentam os maiores valores de índice de risco ambiental (R), indicando a maior necessidade de ações de intervenção - em relação as outras saídas avaliadas - a fim de controlar os impactos ambientais por elas provocadas.

Por outro lado, as demais saídas avaliadas, também importantes, apresentaram menor nível de prioridade, podendo ser minimizadas, por enquanto, por meio de mudanças de posturas. Afinal, deve-se considerar que as ações de controles - aqui propostas - necessitam de recursos financeiros, tecnológicos e humanos para serem implementadas, o que, em geral, não condizem com a realidade de muitas instituições. Entretanto, as mesmas também devem, posteriormente, sofrer ações de controle, pois apesar de apresentarem menor risco ambiental (R), ainda assim também geram impactos ambientais ao meio e interferem no desempenho e eficiência do processo. 
O levantamento dos riscos ambientais frequentes no laboratório gera subsídios em busca de meios para solucionar ou minimizar o problema, além de reduzir os custos do processo. Consequentemente, diante da melhoria do procedimento de trabalho, criam-se condições para que as instituições de pesquisa caminhem em direção à sustentabilidade da atividade e do próprio ambiente de análises químicas em consonância com a legislação ambiental.

Os resultados da pesquisa ratificam que a metodologia FMEA é uma relevante ferramenta para auxiliar a implementação do SGA nas instituições de pesquisa - como o Laboratório de Química do Solo - com a finalidade de propiciar qualidade ambiental à produção. O método FMEA identifica os possíveis ou vigentes riscos e impactos, por nível de criticidade, as causas e as sugestões preventivas e/ou corretivas, cujas falhas procedem do uso e/ou gestão inadequados de recursos - naturais e tecnológicos - e resíduos.

A metodologia FMEA é um relevante instrumento para reconhecer falhas reais ao longo do processo produtivo, permitindo a adoção de ações corretivas, assim como na identificação de falhas potenciais, possibilitando a aplicação de medidas de caráter preventivo, a fim de evitar a ocorrência de futuros problemas que possam prejudicar o desempenho da cadeia de suprimentos. A FMEA demostrou ser eficiente na identificação e avaliação dos riscos ambientais, as causas e os efeitos in loco, possibilitando a proposta de ações preventivas e/ou corretivas e criando subsídios para a implementação do SGA.

\section{REFERÊNCIAS}

ABNT. NBR 10004: Resíduos sólidos: Classificação. Rio de Janeiro: ABNT, 2004a.

ABNT. NBR ISO 14001: Sistemas de gestão ambiental: requisitos com orientações para uso. Rio de Janeiro: ABNT, 2004b.

BRENDLER, E.; BRANDLI, L. L.. Integração do Sistema de Gestão Ambiental no Sistema de Gestão da Qualidade em uma indústria de confecções. Gestão \& Produção, São Carlos, v.18, n.1, p.27-40, 2011. DOI: http://dx.doi.org/10.1590/S0104-530X2011000100003

CARLI, L. N.; CONTO, S. M.; BEAL, L. L.; PESSIN, N.. Racionalização do uso da água em uma Instituição de Ensino Superior - estudo de caso da Universidade de Caxias do Sul. Revista de Gestão Ambiental e Sustentabilidade, São Paulo, v.2, p.143-164, 2013. DOI: http://dx.doi.org/10.5585/geas.v2i1.30

DONAGEMA, G. K.; CAMPOS, D. V. B.; CALDERANO, S. B.; TEXEIRA, W. G.; VIANA, J. H. M.. Manual de métodos de análise de solos. Dados eletrônicos. Rio de Janeiro: Embrapa Solos, 2011.

FRANK, A. G.; PEDRINI, D. C.; ECHEVESTE, M. E.; RIBEIRO, J. L. D.. Integração do QFD e da FMEA por meio de uma sistemática para tomada de decisões no processo de desenvolvimento de produtos. Production, Porto Alegre, v.24, n.2, p.295-310, 2014. DOI: http://dx.doi.org/10.1590/S0103-65132013005000036

GARCIA, P. A. A.. Uma abordagem via análise envoltória de dados para o estabelecimento de melhorias em segurança baseadas na FMEA. Gestão \& Produção, São Carlos, v.20, n.1, p.87-97, 2013. DOI: http://dx.doi.org/10.1590/S0104$\underline{530 \times 2013000100007}$

GRAEL, P. F. F.; OLIVEIRA, O. J.. de Sistemas certificáveis de gestão ambiental e da qualidade: práticas para integração em empresas do setor moveleiro. Revista Produção, Bauru, v.20, n.1, p.30-41, 2010. DOI:

http://dx.doi.org/10.1590/S0103-65132010005000017

LAURENTI, R.; ROZENFELD, H.; FRANIECK, E. K.. Avaliação da aplicação dos métodos FMEA e DRBFM no processo de desenvolvimento de produtos em uma empresa de autopeças. Gestão \& Produção, São Carlos, v.19, n.4, p.841855, 2012. DOI: http://dx.doi.org/10.1590/S0104530X2012000400013

LIMA, C.; PROCHNOW, W. E.. Implantação de Sistema de Gestão Ambiental em empresa do ramo metalúrgico. Revista Meio Ambiente e Sustentabilidade, v.1, n.1, p.114134, 2012.

MARINHO, C. C.; BOZELLI, R. L.; ESTEVES, F. A..

Gerenciamento de resíduos químicos em um Laboratório de Ensino e Pesquisa: a experiência do Laboratório de Limnologia da UFRJ. Eclética Química, São Paulo, v.36, n.2, p.85-104, 2011. DOI: http://dx.doi.org/10.1590/S010046702011000200005

NOGUEIRA, A. C.; PERES, A. P.; CARVALHO, E. M.. Avaliação do risco ambiental utilizando FMEA em um laticínio na região de Lavras-MG. Revista Produção Online, v.11, n.1, p.194-209, 2011. DOI: http://doi.org/10.14488/16761901.v11i1.543

OLIVEIRA, O. J.; PINHEIRO, C. R. M. S.. Implantação de 
Sistemas de Gestão Ambiental ISO 14001: uma contribuição da área de gestão de pessoas. Gestão \& Produção, São Carlos, v.17, n.1, p.51-61, 2010. DOI: http://dx.doi.org/10.1590/S0104-530X2010000100005

OLIVEIRA, O. J.; SERRA, J. R.. Benefícios e dificuldades da gestão ambiental com base na ISO 14001 em empresas industriais em São Paulo. Revista Produção, Bauru, v.20, n.3, p.529-438, 2010. DOI: http://dx.doi.org/10.1590/S0103$\underline{65132010005000013}$

OLIVEIRA, U. R.; PAIVA, E. J.; ALMEIDA, D. A.. Metodologia integrada para mapeamento de falhas: uma proposta de utilização conjunta do mapeamento de processos com as técnicas FTA, FMEA e a análise crítica de especialistas. Revista Produção, Guaratinguetá, v.20, n.1, p.77-91, 2010. DOI: http://dx.doi.org/10.1590/S0103-65132010005000004

PENATTI, F. E.; LIMA-GUIMARÃES, S. T.. Avaliação dos riscos e problemas ambientais causados pela disposição incorreta de resíduos de laboratórios. Geografia Ensino \& Pesquisa, Guaratinguetá, v.15, n.1, p.43-52, 2011. DOI: http://dx.doi.org/10.5902/223649947376

ZAMBRANO, T. F.; MARTINS, M. F.. Utilização do método FMEA para avaliação do risco ambiental. Gestão \& Produção, São Carlos, v.14, n.12, p.295-309, 2007. DOI: http://dx.doi.org/10.1590/S0104-530X2007000200008

A CBPC - Companhia Brasileira de Produção Científica (CNPJ: 11.221.422/0001-03) detém os direitos materiais desta publicação. Os direitos referem-se à publicação do trabalho em qualquer parte do mundo, incluindo os direitos às renovações, expansões e disseminações da contribuição, bem como outros direitos subsidiários. Todos os trabalhos publicados eletronicamente poderão posteriormente ser publicados em coletâneas impressas sob coordenação da Sustenere Publishing, da Companhia Brasileira de Produção Científica e seus parceiros autorizados. Os (as) autores (as) preservam os direitos autorais, mas não têm permissão para a publicação da contribuição em outro meio, impresso ou digital, em português ou em tradução. 